Supplement of Atmos. Chem. Phys., 14, 8235-8254, 2014

http://www.atmos-chem-phys.net/14/8235/2014/

doi:10.5194/acp-14-8235-2014-supplement

(C) Author(s) 2014. CC Attribution 3.0 License.

(c) (i)

Atmospheric

Chemistry

and Physics

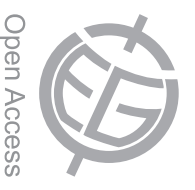

Supplement of

\title{
Transport of aerosol to the Arctic: analysis of CALIOP and French aircraft data during the spring 2008 POLARCAT campaign
}

G. Ancellet et al.

Correspondence to: G. Ancellet (gerard.ancellet@upmc.fr) 

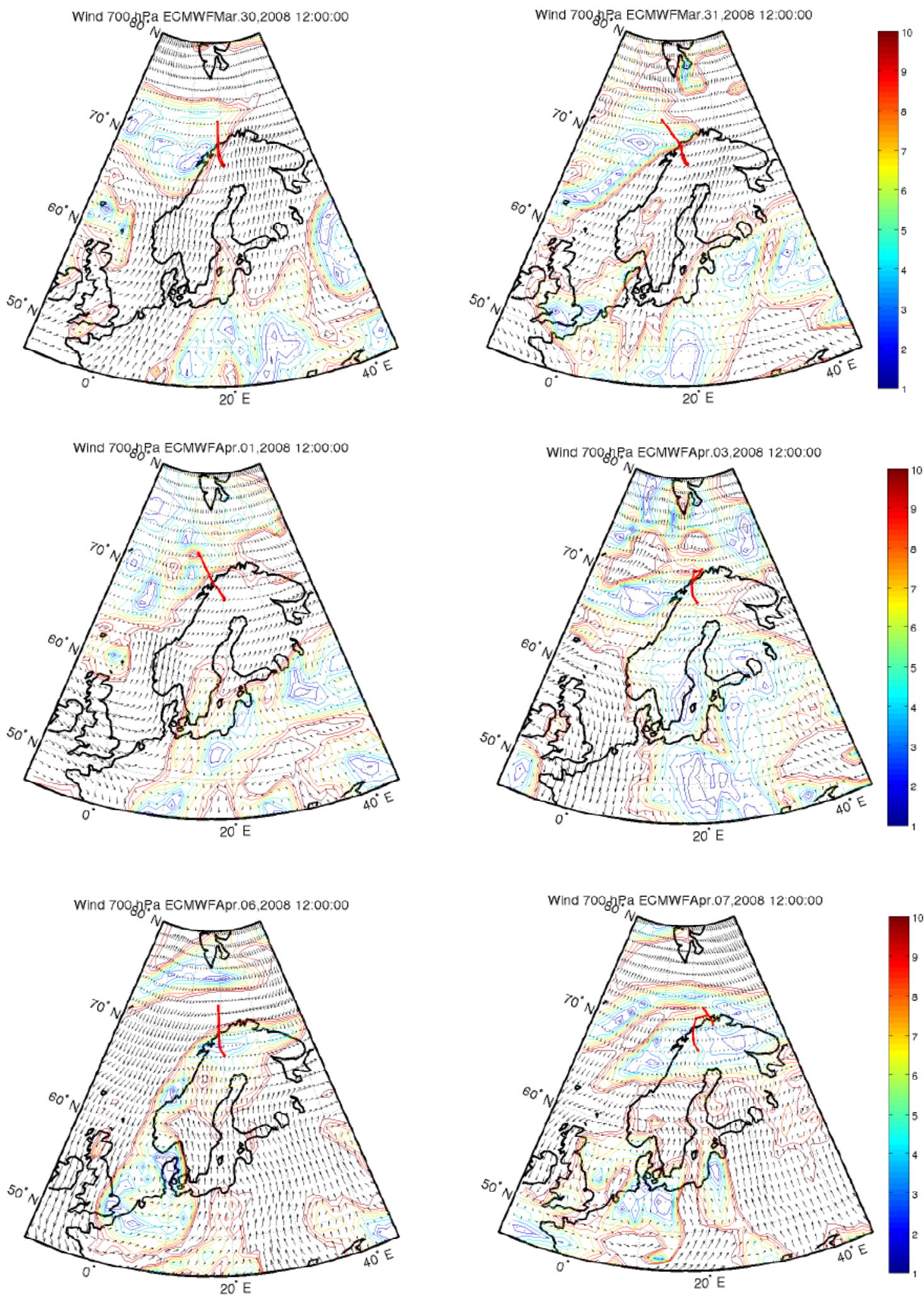

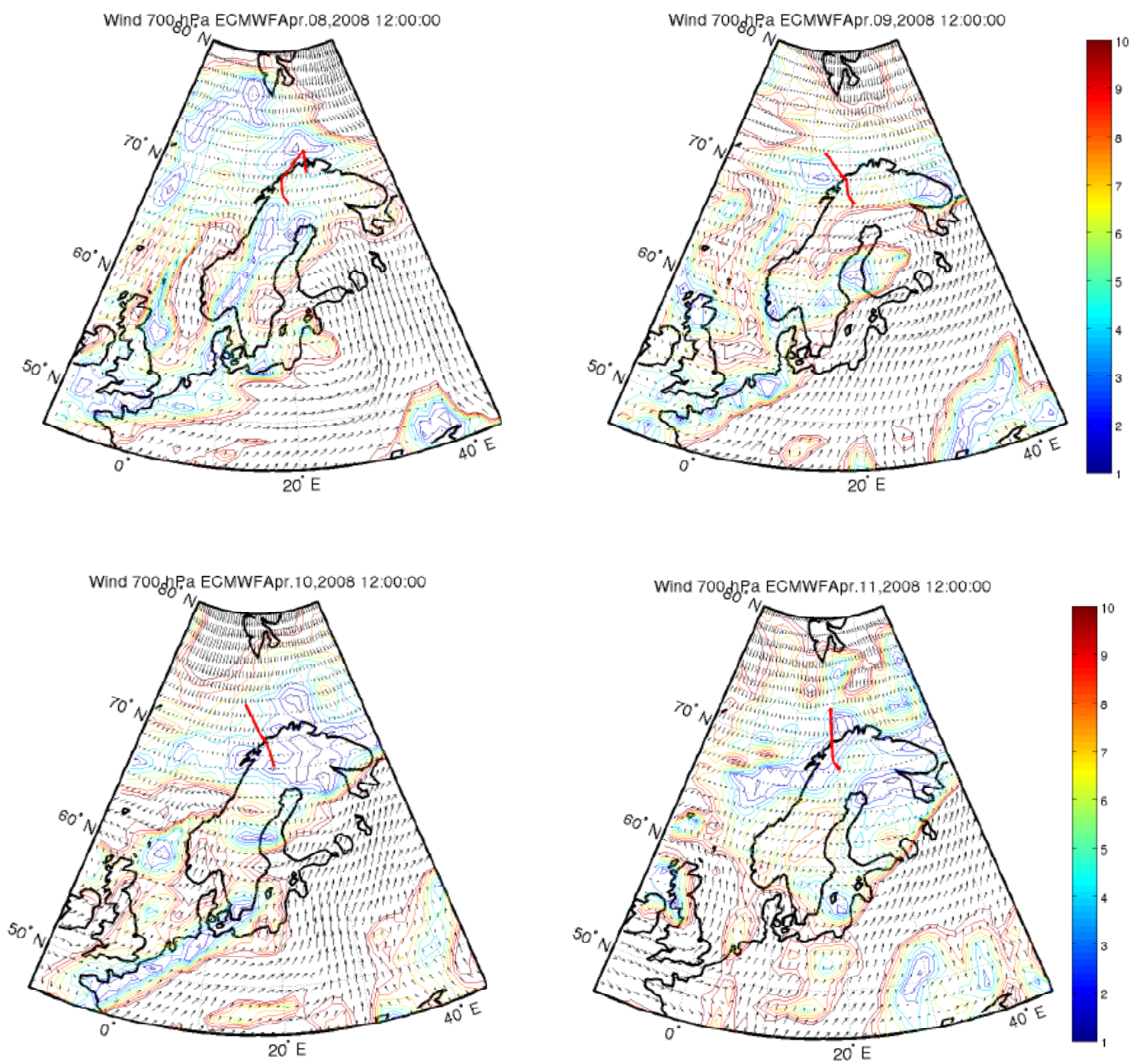

Figure 1 Wind field at $700 \mathrm{hPa}, 12: 00 \mathrm{UT}$ from March 30 to April 11 for the aircraft flights listed in Table 1 . The color scale corresponds to the wind intensity in $\mathrm{m}_{\mathrm{s}}{ }^{-1}$
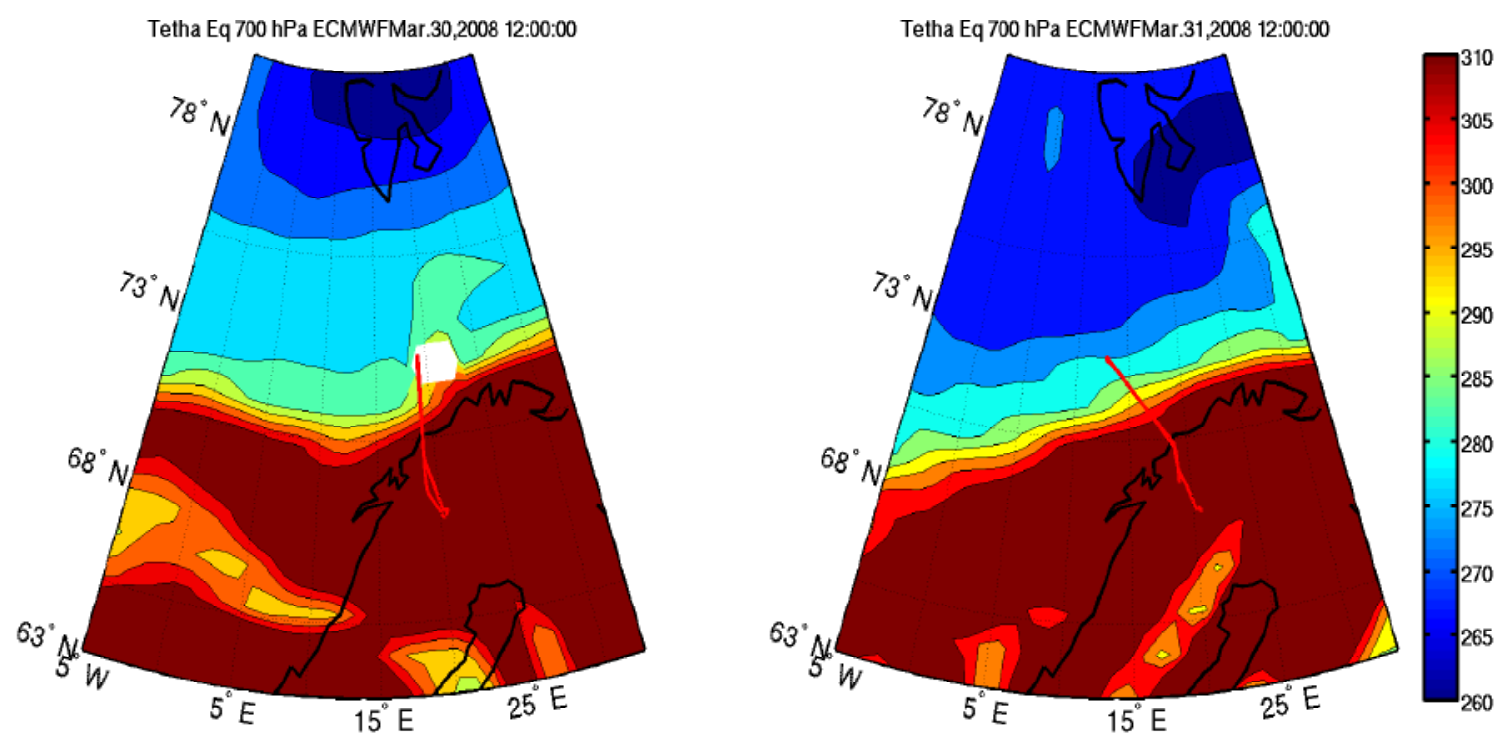

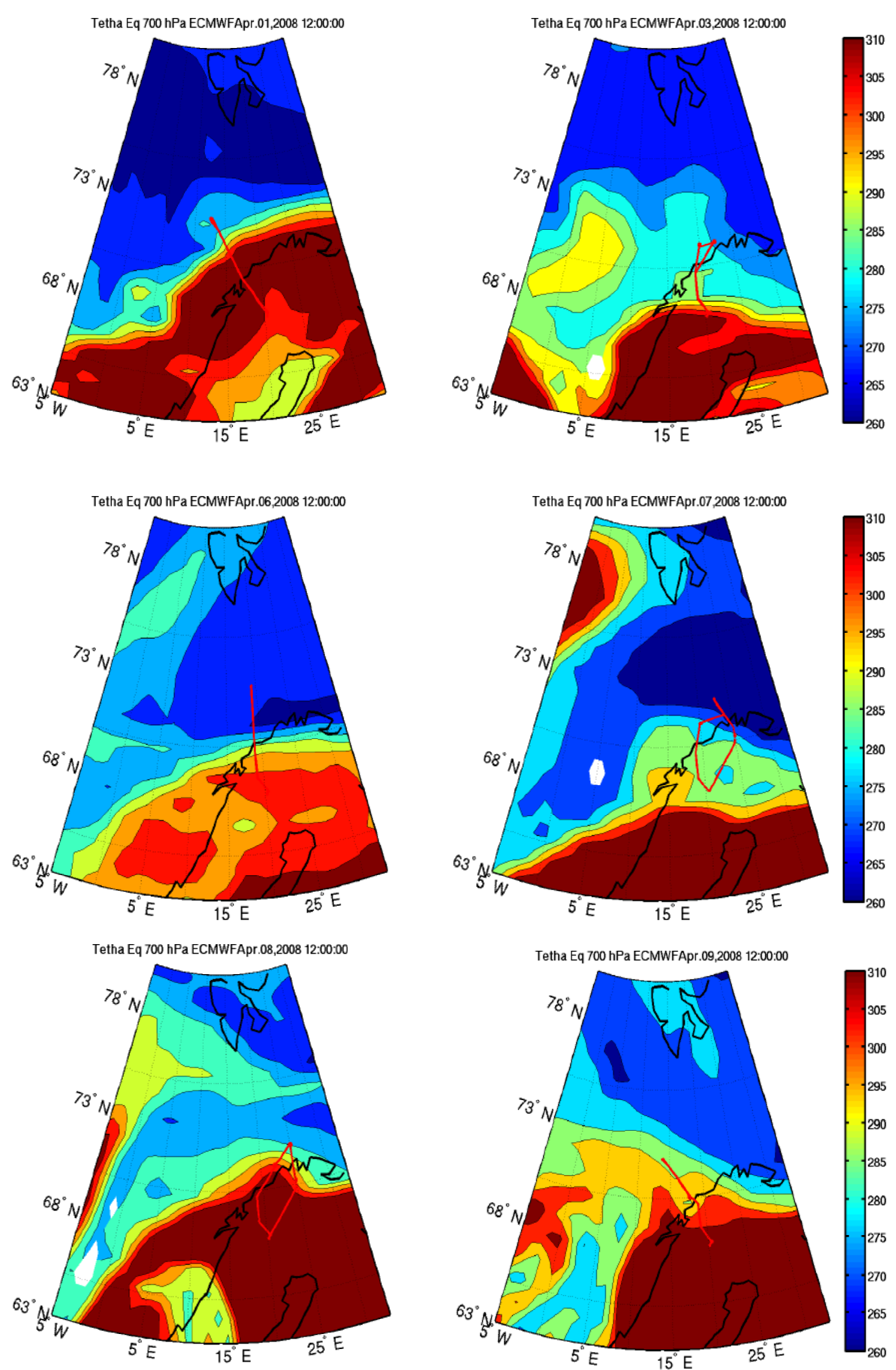

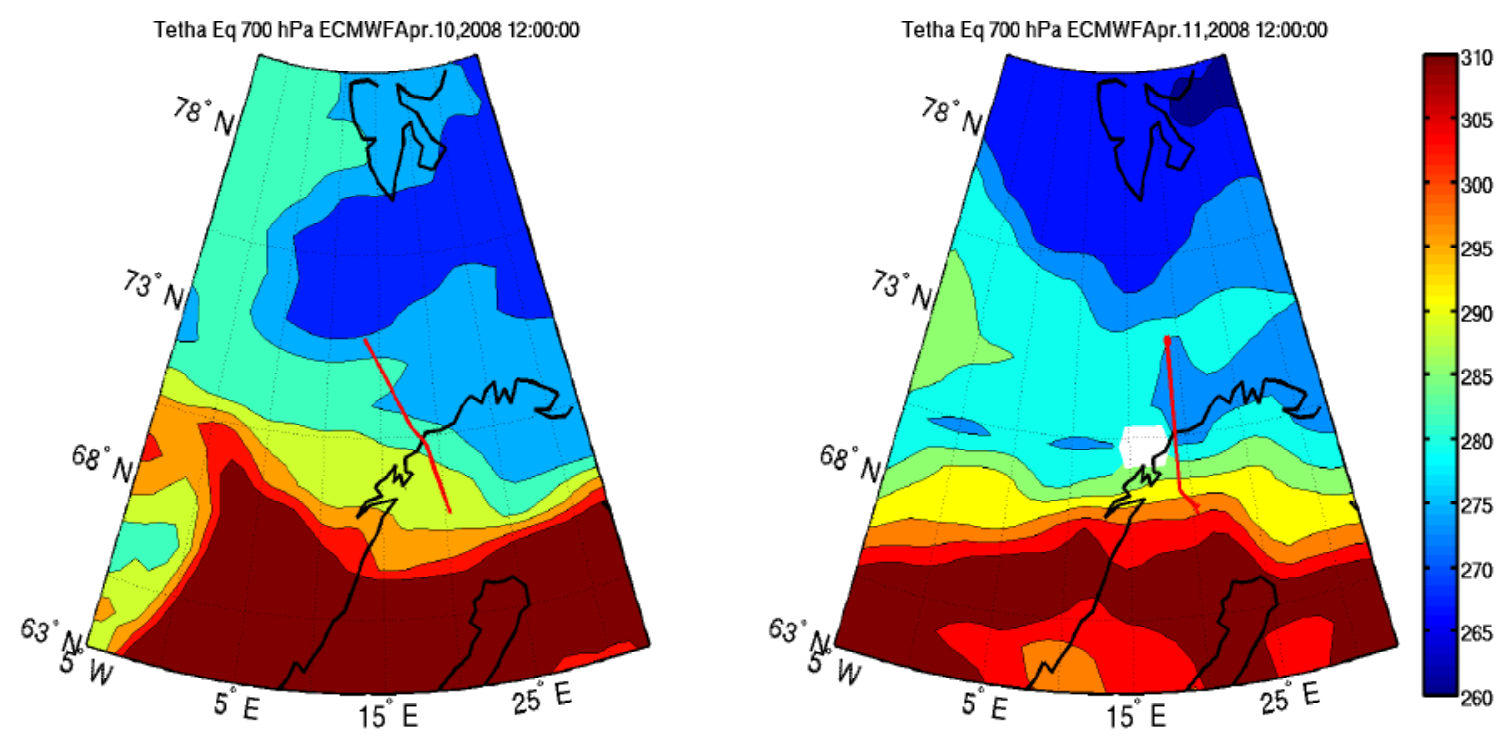

Figure 2: Equivalent potential temperature in $\mathrm{K}$ at $700 \mathrm{hPa}, 12: 00 \mathrm{UT}$ from March 10 to April 11 for the aircraft flights listed in Table 1
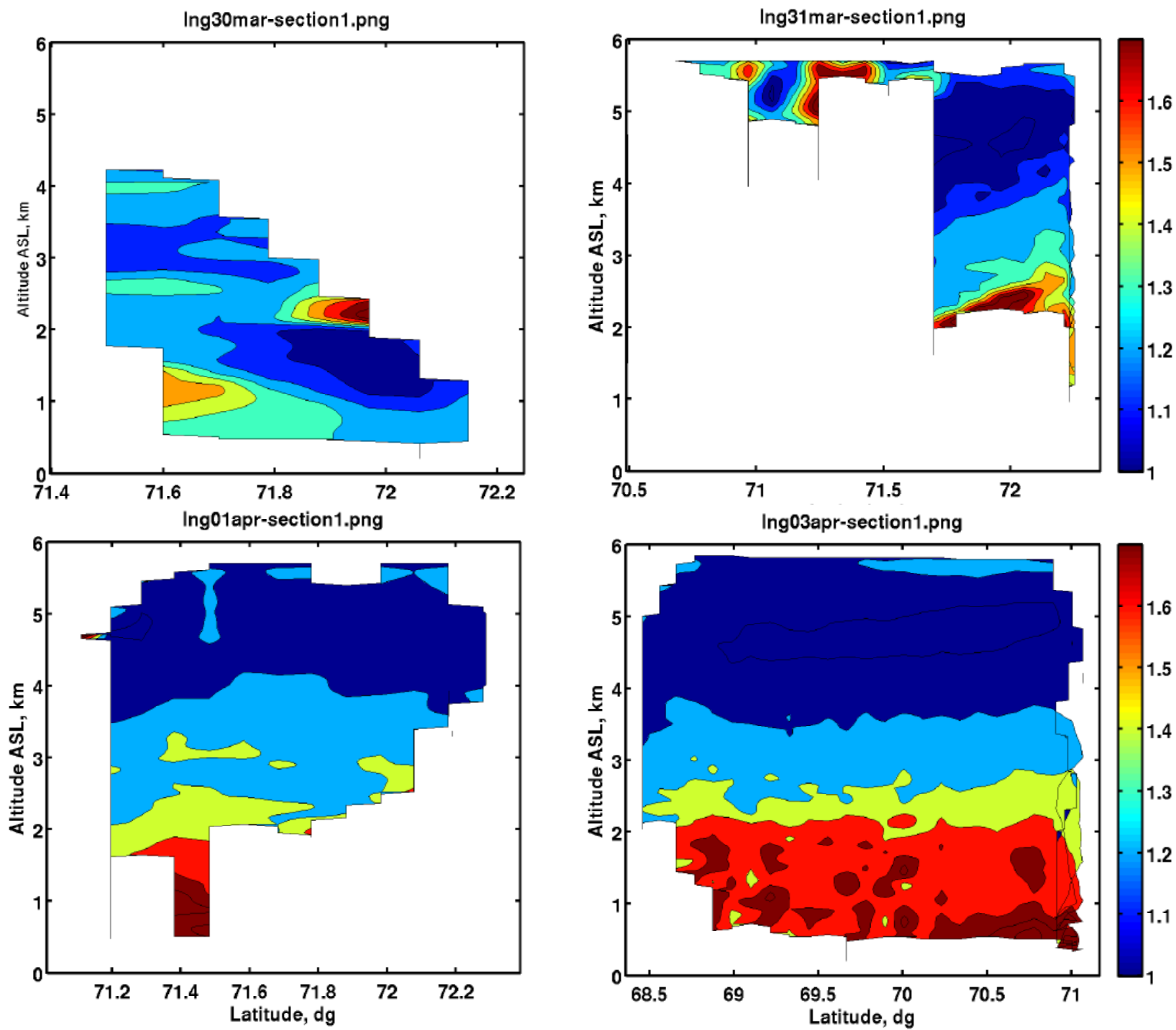

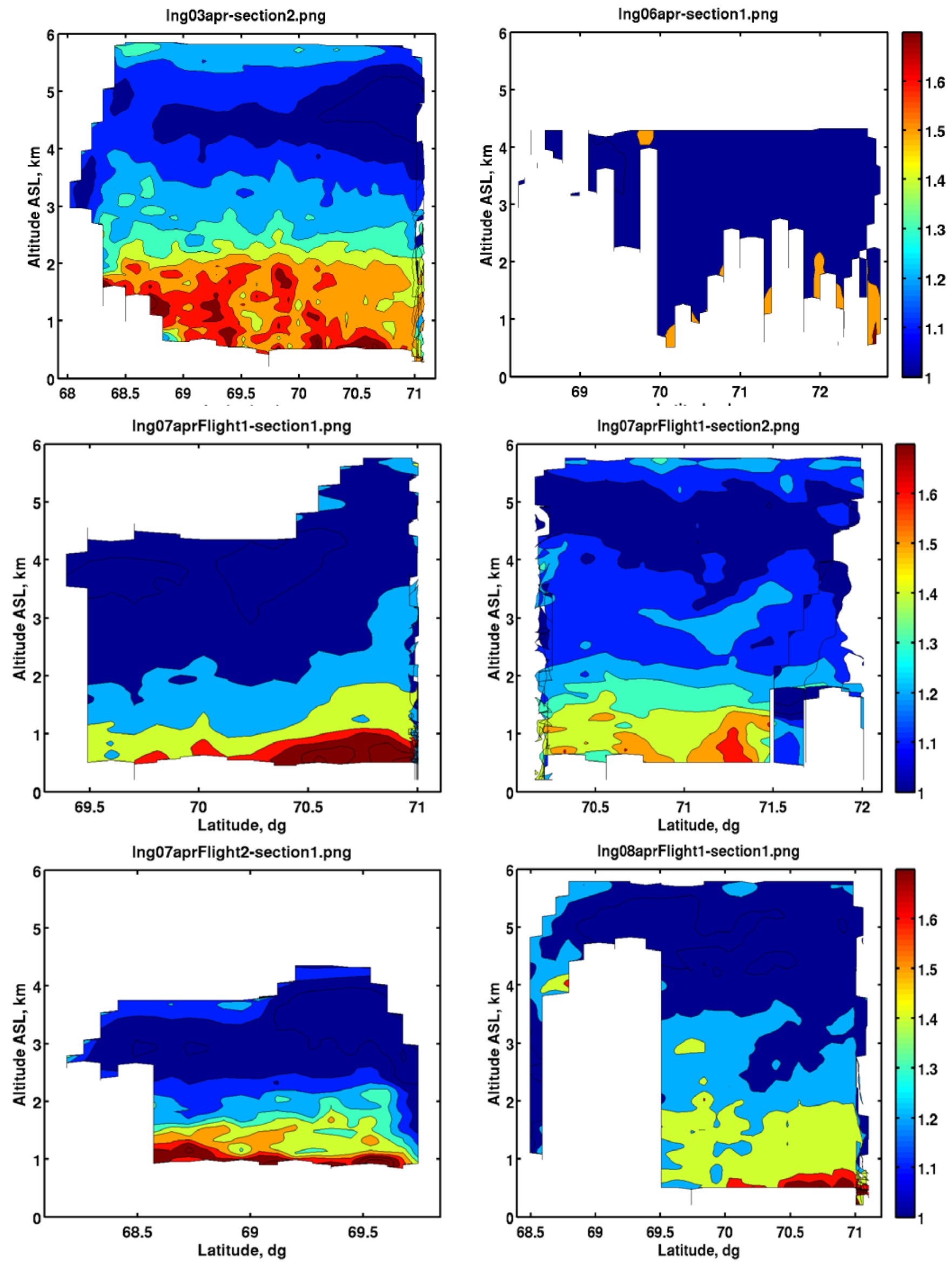

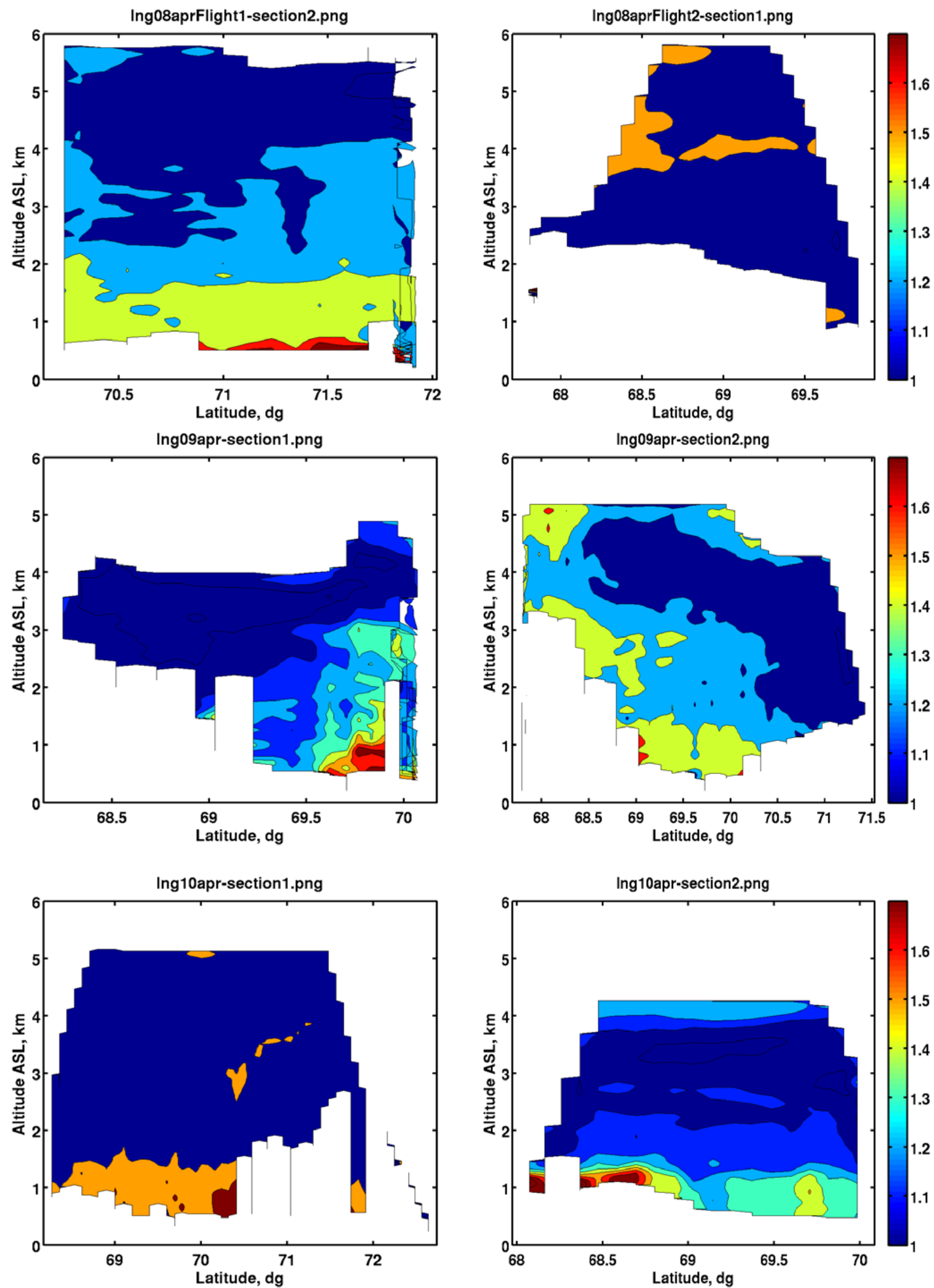

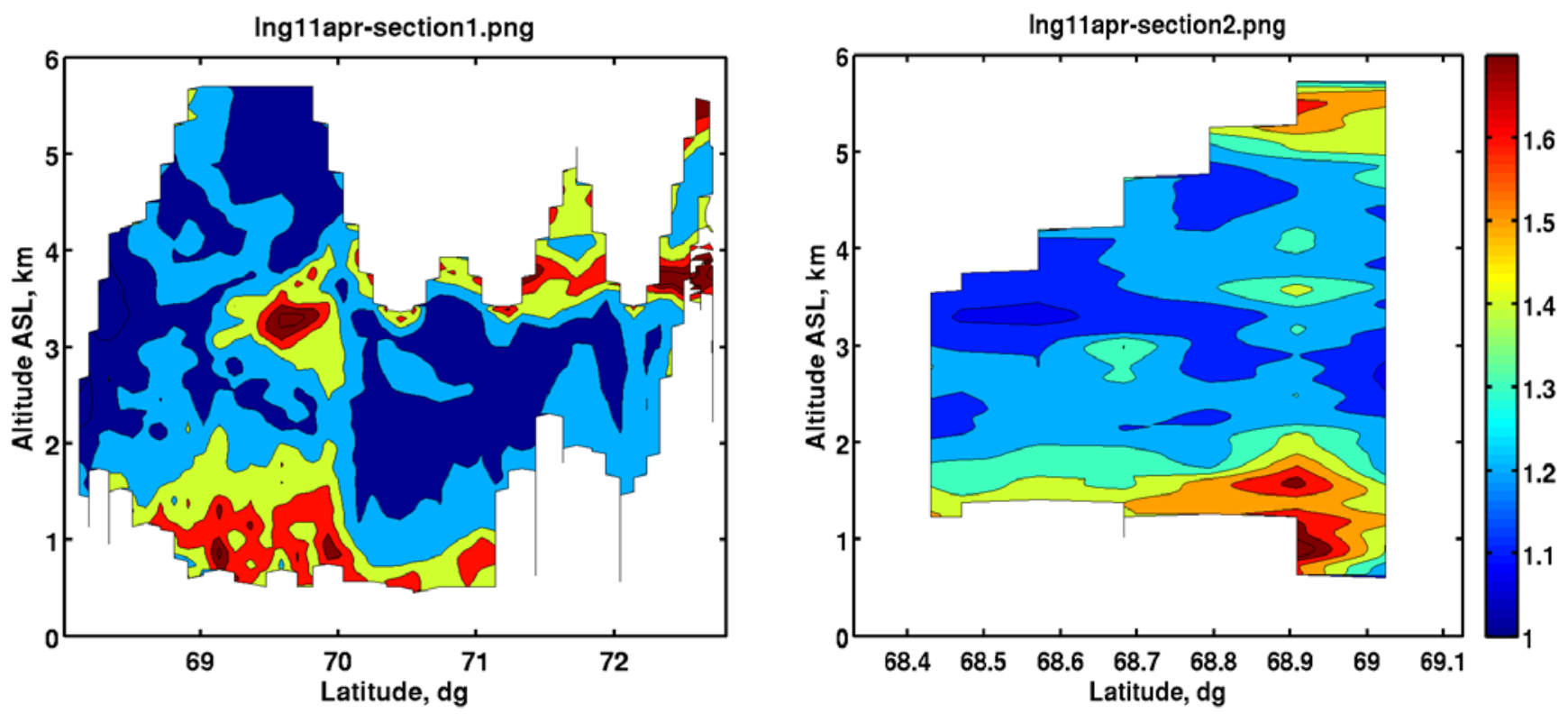

Fig. 3 Vertical cross sections of the airborne lidar $532 \mathrm{~nm}$ backscatter ratio for the aircraft meridional cross section from 30 March to 7 April listed in Table 1. 